Photogallery

\title{
Updated northern distributional limits of Acropora spp. along the Kuroshio Current
}

\section{Masako NAKAMURA* and Hiroyuki YOKOCHI}

School of Marine Science and Technology, Tokai University, Shimizu, Shizuoka 424-8610, Japan

* Corresponding author: Masako Nakamura

E-mail: mnakamura@tsc.u-tokai.ac.jp

Communicated by Hironobu Fukami (Biodiversity Editor)

Keywords Acropora, northward progression, Shizuoka

Climate change drives the distributional limits of marine flora and fauna to higher latitudes by increasing average winter seawater temperatures. This phenomenon has been observed in reef-building corals in the Australian region, the Mediterranean Sea, and the Japanese region. In October 2019, two Acropora species were observed in Nishiura, along the northwestern coast of the Izu peninsula $\left(\sim 35^{\circ} 0^{\prime} \mathrm{N}\right)$ in Shizuoka Prefecture, Japan (Fig. 1). This was the first record for these species around the peninsula. One was a widely-distributed species, Acropora hyacinthus, which was previously known from the subtropical Ryukyu Islands (Okinawa Prefecture) to temperate Shikinejima, in the Izu Islands in Shizuoka Prefecture $\left(\sim 24^{\circ} 1^{\prime}\right.$ to $\sim 34^{\circ} 2^{\prime} \mathrm{N}$; Nakabayashi et al. 2019). This colony may belong to the A. hyacinthus lineage HyaD (Suzuki et al. 2016) because all A. hyacinthus colonies from the mainland of Japan, examined in Suzuki et al. (2016), belonged to lineage HyaD. The other was a temperate species, A. japonica, which has been recorded from subtropical Tanegashima (Kagoshima Prefecture) to temperate Wakayama Prefecture ( $\sim 30^{\circ} 3^{\prime}$ to $\sim 33^{\circ} 2^{\prime}$ N; Nomura et al. 2016). The observed colonies were large enough to have distinguishable morphological characteristics. One colony of $A$. hyacinthus was $\sim 17.5 \mathrm{~cm}$ and four colonies of $A$. japonica were $23.1 \sim 37.1 \mathrm{~cm}$ in their longest dimension. While acroporid corals at high-latitude locations grow at $6 \sim 10 \mathrm{~cm} /$ year in diameter with tank experiment, keeping the water temperature at $25 \sim 26$ ${ }^{\circ} \mathrm{C}$ (Hayashi and Iwase 2010), the $A$. hyacinthus colony in Nishiura may grow slower due to lower seawater temperature and may have been recruited more than 3 years ago, and the $A$. japonica colonies probably became established earlier.

These records document the northward progression of distributional ranges for Acropora spp. Since populations of $A$. hyacinthus in subtropical and temperate areas along the Kuroshio Current are connected by multi-generation dispersal (Nakabayashi et al. 2019), populations of these Acropora spp. in Nishiura probably became established due to poleward larval dispersal. The average winter temperature in Nishiura has been fluctuating around $13 \sim 16^{\circ} \mathrm{C}$ for more than 25 years. However, in the last five years, it has remained above $15^{\circ} \mathrm{C}$. Moreover, it was $16.4^{\circ} \mathrm{C}$ in 2019 . These relatively high average winter temperatures around the Izu Peninsula would facilitate survival of recently settled larvae.

\section{Acknowledgements}

We thank Kousuke Takadou, Mikito Ishida, and Yasuyuki Matsunaga for helping to conduct this survey. 




Fig. 1 A and B. Acropora hyacinthus, C and D. Acropora japonica.

\section{References}

Hayashi T, Iwase F (2010) Growth and maturation of the artificially bred Acropora hyacinthus in Shikoku, Japan. Kuroshio Biosphere 6: 15-26

Nakabayashi A, Yamakita T, Nakamura T, Aizawa H, Kitano YF, Iguchi A, Yamano H, Nagai S, Agostini S, Teshima KM, Yasuda N (2019) The potential role of temperate Japanese regions as refugia for the coral Acropora hyacinthus in the face of climate change. Scientific Reports 9: 1892

Nomura K, Fukami H, Zayasu Y, Shimada G, Kitano Y, Yokochi H, Shimoike K, Tachikawa H, Oku Y, Suzuki G, Kajiwara K (2016) Revision of the zooxanthellate scleractinian corals in Kushimoto, Wakayama, Japan (in Japanese). Marine Pavilion, Supplement 4: 1-20

Suzuki G, Keshavmurthy S, Hayashibara T, Wallace CC, Shirayama Y, Chen CA, Fukami H (2016) Genetic evidence of peripheral isolation and low diversity in marginal populations of the Acropora hyacinthus complex. Coral Reefs 35: $1419-1432$ 